\title{
Decelerated DNA methylation age predicts poor prognosis of breast cancer
}

\author{
Jun-Ting Ren ${ }^{1,4 \dagger}$, Mei-Xia Wang ${ }^{1 \dagger}$, Yi Su$^{2}$, Lu-Ying Tang ${ }^{3}$ and Ze-Fang Ren ${ }^{1 *}$ (D)
}

\begin{abstract}
Background: DNA methylation (DNAm) age was found to be an indicator for all-cause mortality, cancer incidence, and longevity, but no study has involved in the associations of DNAm age with the prognosis of breast cancer.

Methods: We retrieved information of 1076 breast cancer patients from Genomic Data Commons (GDC) data portal on March 30, 2017, including breast cancer DNAm profiling, demographic features, clinicopathological parameters, recurrence, and all-cause fatality. Horvath's method was applied to calculate the DNAm age. Cox proportional hazards regression models were used to test the associations between DNAm age of the cancerous tissues and the prognosis (recurrence of breast cancer and all-cause fatality) with or without adjusting for chronological age and clinicopathological parameters.

Results: The DNAm age was markedly decelerated in the patients who were premenopausal, ER or PR negative, HER2-enriched or basal-like than their counterparts. In the first five-year follow-up dataset for survival, every ten-year increase in DNAm age was associated with a 15\% decrease in fatality; subjects with DNAm age in the second (HR: 0.52; 95\%Cl: 0.29-0.92), the third (HR: 0.49; 95\%Cl: 0.27-0.87) and the fourth quartile (HR: $0.38 ; 95 \% \mathrm{Cl}: 0.20-0.72$ ) had significant longer survival time than those in the first quartile. In the first five-year follow-up dataset for recurrence, every ten-year increase in DNAm age was associated with a $14 \%$ decrease of the recurrence; in the categorical analysis, a clear dose-response was shown ( $P$ for trend $=0.02$ ) and the fourth quartile was associated with a longer recurrence free survival (HR: 0.32; 95\%Cl: 0.14-0.74). In the full follow-up dataset, similar results were obtained.
\end{abstract}

Conclusions: DNAm age of breast cancer tissue, which associated with menopausal status and pathological features, was a strong independent predictor of the prognosis. It was suggested that the prognosis of breast cancer was related to intrinsic biological changes and specific molecular targets for treatment of breast cancer may be implicit.

Keywords: DNA methylation age, Breast cancer, Prognosis

\section{Background}

Ageing presents numerous progressive changes in molecular, cellular, tissular and organismal functions, which ultimately drives various diseases and limits lifespan [1]. Consequently, age has been confirmed to be the strongest demographic risk factor for most common chronic human diseases, including cancers [2]. Ageing indicates accumulation of somatic mutations as well as aberrant epigenetic changes (epimutations) [3, 4]. Based on DNA methylation data, an age estimator (referred to as DNAm age) has been developed to accurately estimate

\footnotetext{
* Correspondence: renzef@mail.sysu.edu.cn

†Jun-Ting Ren and Mei-Xia Wang contributed equally to this work.

${ }^{1}$ The School of Public Health, Sun Yat-sen University, 74 Zhongshan 2nd

Road, Guangzhou 510080, People's Republic of China

Full list of author information is available at the end of the article
}

chronological age across multiple normal tissues $[5,6]$. An increasing body of literatures reported that the DNAm age was able to capture the aspects of the biological age of the underlying normal tissue and predict the susceptibility to various health outcomes. For example, the DNAm age of blood was predictive of allcause mortality [7-11], cancer incidence [12-17], and longevity [10].

For malignant tumor tissues, however, the DNAm age was not able to estimate the chronological age of the host [6]. This may be because DNAm pattern in the clones of cancer origination is different from that of normal tissue and it only presents the state of ageing in the

(c) The Author(s). 2018 Open Access This article is distributed under the terms of the Creative Commons Attribution 4.0 International License (http://creativecommons.org/licenses/by/4.0/), which permits unrestricted use, distribution, and reproduction in any medium, provided you give appropriate credit to the original author(s) and the source, provide a link to the Creative Commons license, and indicate if changes were made. The Creative Commons Public Domain Dedication waiver (http://creativecommons.org/publicdomain/zero/1.0/) applies to the data made available in this article, unless otherwise stated. 
tumor cells [18]. It was exhibited that stem cells had the lowest DNAm age and this age increased when they differentiated into more mature cells [6]. Moreover, the cancer new clones develop with a wide variation, which consequently induces huge inter- and intra- heterogeneity in cancer tissues, including both the genomics and epigenomics [19]. Therefore, we speculate that the DNAm age of cancer cells may present the capacity to differentiate into malignant clones and can predict the outcome of the disease. Till now, only one study have involved in the associations of DNAm age in malignant diseases with the prognosis, while breast cancer was not included [18]. The role of DNAm age in tumor tissues in predicting the prognosis of cancer patients is far from being confirmed.

In the present study, we focused on breast cancer and comprehensively analyzed whether the DNAm age in tumor tissues was associated with the prognosis when taking the chronological age and the clinicopathological features into account, using the datasets from the Cancer Genome Atlas (TCGA) data portal.

\section{Methods}

\section{Datasets}

We retrieved all available breast cancer DNAm profiles on Infinium Human Methylation 450 Bead Chip or Human Methylation 27 Bead Chip (Illumina Inc.) from Genomic Data Commons (GDC) data portal (https://portal.gdc.cancer.gov/) with TCGA datasets using the R/Bioconductor TCGAbiolinks package [20] (https://www.bioconductor.org/). Corresponding demographic characteristics (gender, chronological age, menopausal status, and race), clinicopathological parameters (tumor stage and subtypes), follow up data (recurrence, all-cause fatality) were also downloaded from GDC on March 30, 2017. Thus, the present study dataset contains 1085 breast cancer DNAm profiles for 1076 female patients (9 subjects had double profiles which were averaged). Other 122 DNAm profiles for adjacent normal breast tissues were also included in the dataset to demonstrate the accuracy of the estimation method on chronological age. Only 889 of these female breast cancer patients had recurrence free survival information which was obtained from UCSC Xena (http://xena.ucsc.edu/).

\section{DNAm age calculation}

We applied Horvath's method to calculate the DNAm age [6], which is currently the most robust predictor of chronological age [21]. Briefly, 353 dinucleotide markers were selected from 21,369 CpG probes on the Illumina $27 \mathrm{~K}$ and $450 \mathrm{~K}$ platforms with a penalized regression model in a large sample $(n=8000)$, including 51 healthy tissues and cell types and covering the entire adult life span. These markers were weighted to estimate the
DNAm age (in units of years). It shows high age correlations $(r=0.96)$ and small mean deviation from calendar age (3.6 years) in its validation cohort. Mathematical details and software tutorials for DNAm age calculation can be found in the Additional files of Horvath [6]. An online age calculator (https://dnamage.genetics.ucla.edu) is available, by which the DNAm ages for the adjacent normal tissues and the cancerous tissues from the breast cancer patients in the dataset were obtained.

\section{Statistics}

Scatter plots were generated to illustrate the relationship between chronological age and DNAm age in the adjacent normal tissues and cancerous tissues. Pearson correlation coefficient ( $r$ ) between chronological and DNAm ages were computed accordingly. Cox proportional hazards regression models were used to test the associations between DNAm age of the cancerous tissues and the prognosis (recurrence of breast cancer and all-cause fatality). Hazard Ratios (HRs) and corresponding 95\% confidence intervals (CIs) were calculated. Three models were applied: 1) no adjustment, 2) adjusted only for chronological age (continuous), and 3) further adjusted for race, clinical stage, menopause status, estrogen receptor (ER), human epidermal growth factor receptor 2 (HER2), and PAM50 subtype. DNAm age was regarded as either a linear function expressed by per ten-year increase or category of quartile.

Four endpoints were applied to present the prognosis: 1) overall survival (full follow-up), 2) five-year survival (the first five-year follow-up), 3) overall recurrence free survival (full follow-up), and 4) five-year recurrence free survival (the first five-year follow-up). Five-year survival and recurrence free survival were generated from the original dataset by censoring patients who died after five-year follow-up and limiting survival time to 5 years for patients who survived for more than 5 years.

Stratified analyses for the associations were performed by race, menopausal status and pathological characteristics of HER2, ER, PAM50 subtype, and clinical stage. The interactions between DNAm age and stratified variables were evaluated by adding an interaction term in the Cox model, which was tested by Wald test. All statistical tests were two-tailed with $P<0.05$ considered to be significant. Statistical analyses were conducted using R software version 3.3.2 (https://www.r-project.org/).

\section{Results}

Relationship between chronological age and DNAm age As shown in Fig. 1, the Pearson correlation coefficients between DNAm age and chronological age were $0.85(p<$ $0.01)$ for breast normal tissues and $0.30(p<0.01)$ for breast cancerous tissues. The median absolute deviations (ranges of the difference between DNAm age and chronological 

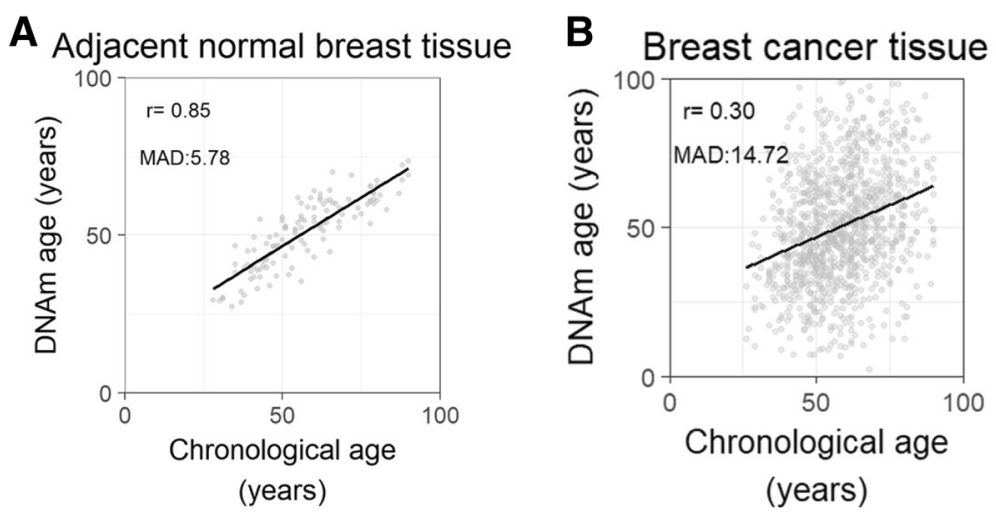

Fig. 1 Correlations between DNAm age and chronological age. a DNAm age of 122 adjacent normal breast tissues from breast cancer patients can predict chronological age with decent accuracy. The median absolute deviation (MAD) and range of the difference between DNAm age and chronological age were 5.78 years and-24.94 to 12.02 years, respectively. b DNAm age of 1097 breast cancers was poorly correlated with patients' chronological age. The MAD and range of the difference between DNAm age and chronological age were 14.72 years and -67.35 to 91.38 years, respectively

age) were 5.78 (-24.94 to 12.02$)$ years and $14.72(-67.35$ to 91.38 ) years for normal tissues and cancerous tissues, respectively.

\section{Characteristics and the relationships with DNAm age in breast cancer tissues}

The demographic and clinicopathological characteristics for 1076 female breast cancer patients were shown in Table 1 . The majority of the patients were over 40 years old. Chronological age, in a way of categorical variable, was positively associated with DNAm age. The African American patients had a significant lower DNAm age than the whites or others. The DNAm age was markedly decelerated among the patients who were premenopausal, ER or PR negative, HER2-enriched or basal-like than their corresponding counterparts.

\section{Associations between DNAm age and prognosis}

During the full follow-up period, 151 all-cause deaths were recorded in all patients and 96 cases recurred in 889 patients with recurrence data. During the first fiveyear follow-up period, 98 and 79 patients were recorded for all-cause deaths and recurrence, respectively.

When survival as an outcome, older DNAm age was associated with longer survival, and this association was more evident in the first five-year follow-up dataset, in which every ten-year increase in DNAm age was associated with a $15 \%$ decrease in fatality in the full adjustment model (HR: 0.85; 95\%CI: 0.76-0.96) (Table 2). Compared with the first quartile, the second (HR: 0.52; CI: 0.29-0.92), the third (HR: 0.49; 95\%CI: $0.27-0.87$ ), and the fourth quartile (HR: 0.38 ; 95\%CI: $0.20-0.72$ ) were all associated with a longer survival in the first five-year follow-up dataset, and the $P$ value for trend was significant $(P=0.004)$. In addition, compared with the first quartile, the combined three upper quartiles were also associated with a longer survival (HR: 0.47; 95\%CI: 0.29-0.76). For all the endpoints, the associations between DNAm age and breast cancer prognosis were stronger after adjusted for chronological age.

When recurrence free survival as an outcome, it was similarly shown that higher DNAm age was associated with a longer recurrence-free survival (Table 3). Every ten-year increase in DNAm age was significantly associated with a $14 \%$ decrease of the recurrence for both datasets of full and five-year follow-up in the full adjustment model. In the categorical analysis, a significant dose-response relationship was shown $(P$ for trend $<0.05)$ and the fourth quartile was associated with a longer recurrence-free survival [HR (95\%CI): 0.39 (0.19-0.80) and 0.32; 0.14-0.74 for full follow-up and five-year follow-up, respectively)], although the combined three upper quartiles were not significantly associated with recurrence-free survival when compared with the first quartile.

Stratified analyses were further performed to assess whether the associations between the DNAm age and the prognosis of breast cancer were modified by clinicalpathological characteristics and menopausal status (Table 4). Although the interactions did not reach the level of statistical significance, the subgroups showed considerable differences in HR estimates when stratified by menopause status. The HR and 95\% CI (three upper combined quartiles vs. first quartile DNAm age) were $0.40(0.24-0.69)$ in post-menopausal patients and 0.87 $(0.30-2.58)$ in pre-menopausal patients for overall survival, and the HR and 95\% CI were $0.58(0.29-1.16)$ and $1.16(0.42-3.21)$ for recurrence-free survival, respectively. A similar result was shown for HER2 status; the association of higher DNAm age with a better prognosis was stronger in HER2 positive than negative patients. 
Table 1 Demographic and clinicopathological characteristics and the associations with DNA methylation age for 1076 female breast cancer patients $(\mathrm{N}, \%)$

\begin{tabular}{|c|c|c|c|c|c|c|}
\hline \multirow[t]{2}{*}{ Characteristics } & \multirow[t]{2}{*}{ Total } & \multicolumn{4}{|c|}{ DNAm age (quartile) ${ }^{b}$} & \multirow{2}{*}{$\begin{array}{l}P \\
\text { value } \\
a\end{array}$} \\
\hline & & First & Second & Third & Fourth & \\
\hline \multicolumn{7}{|l|}{ Age (years) } \\
\hline$<40$ & $96(8.9)$ & $52(19.3)$ & $20(7.4)$ & $13(4.8)$ & $11(4.1)$ & \multirow[t]{3}{*}{$<0.01$} \\
\hline $40-60$ & $496(46.1)$ & $145(53.9)$ & $148(55.0)$ & $115(42.8)$ & $88(32.7)$ & \\
\hline$>60$ & $484(45.0)$ & $72(26.8)$ & $101(37.5)$ & $141(52.4)$ & $170(63.2)$ & \\
\hline \multicolumn{7}{|l|}{ Race } \\
\hline African American & $178(16.5)$ & $72(26.8)$ & $40(14.9)$ & $35(13.0)$ & $31(11.5)$ & \multirow[t]{2}{*}{$<0.01$} \\
\hline White or other & 898 (83.5) & $197(73.2)$ & $229(85.1)$ & $234(87.0)$ & $238(88.5)$ & \\
\hline \multicolumn{7}{|l|}{ Menopausal status } \\
\hline Premenopausal & $229(21.3)$ & $80(29.7)$ & $57(21.2)$ & $54(20.1)$ & $38(14.1)$ & \multirow[t]{3}{*}{$<0.01$} \\
\hline Post-menopausal & $736(68.4)$ & $153(56.9)$ & $185(68.8)$ & $187(69.5)$ & $211(78.4)$ & \\
\hline Unknown & $111(10.3)$ & $36(13.4)$ & $27(10.0)$ & $28(10.4)$ & $20(7.4)$ & \\
\hline \multicolumn{7}{|l|}{ ER } \\
\hline Negative & $178(16.6)$ & 99 (36.8) & $53(19.7)$ & $20(7.4)$ & $6(2.2)$ & \multirow[t]{3}{*}{$<0.01$} \\
\hline Positive & $588(54.6)$ & $95(35.3)$ & $140(52.0)$ & $161(59.9)$ & $192(71.4)$ & \\
\hline Unknown & $310(28.8)$ & 75 (27.9) & $76(28.3)$ & $88(32.7)$ & $71(26.4)$ & \\
\hline \multicolumn{7}{|l|}{ PR } \\
\hline Negative & $251(23.3)$ & $122(45.4)$ & $67(24.9)$ & $36(13.4)$ & $26(9.7)$ & \multirow[t]{3}{*}{$<0.01$} \\
\hline Positive & $512(47.6)$ & $70(26.0)$ & $126(46.8)$ & $145(53.9)$ & $171(63.6)$ & \\
\hline Unknown & $313(29.1)$ & $77(28.6)$ & $76(28.3)$ & $88(32.7)$ & $72(26.7)$ & \\
\hline \multicolumn{7}{|l|}{ HER2 } \\
\hline Negative & $644(59.9)$ & $156(58.0)$ & $162(60.2)$ & $155(57.6)$ & $171(63.5)$ & \multirow[t]{3}{*}{0.33} \\
\hline Equivocal/positive & $118(11.0)$ & $37(13.7)$ & $31(11.5)$ & $24(9.0)$ & $26(9.7)$ & \\
\hline Unknown & $314(29.1)$ & $76(28.3)$ & $76(28.3)$ & $90(33.4)$ & $72(26.8)$ & \\
\hline \multicolumn{7}{|l|}{ PAM50 } \\
\hline Luminal A & $229(21.3)$ & $25(9.3)$ & $51(19.0)$ & $71(26.4)$ & $82(30.5)$ & \multirow[t]{4}{*}{$<0.01$} \\
\hline Luminal B & $122(11.3)$ & $22(8.2)$ & $25(9.3)$ & $28(10.4)$ & $47(17.5)$ & \\
\hline HER2-enriched \& Basal-like & $155(14.4)$ & $84(31.2)$ & $41(15.2)$ & $22(8.2)$ & $8(3.0)$ & \\
\hline Unknown & $570(53.0)$ & $138(51.3)$ & $152(56.5)$ & $148(55.0)$ & $132(49.0)$ & \\
\hline \multicolumn{7}{|l|}{ Clinical stage } \\
\hline$|/| \mid$ & $568(52.8)$ & $136(50.6)$ & $149(55.4)$ & $136(50.6)$ & $147(54.6)$ & \multirow[t]{3}{*}{0.26} \\
\hline III/IV & $187(17.4)$ & $56(20.8)$ & $38(14.1)$ & $44(16.3)$ & $49(18.2)$ & \\
\hline Unknown & $321(29.8)$ & 77 (28.6) & $82(30.5)$ & $89(33.1)$ & $73(27.1)$ & \\
\hline
\end{tabular}

\footnotetext{
${ }^{a}$ Pearson chi-squared test. Unknown data was not accounted in the test

${ }^{b}$ Patients were divided into quartiles according to DNAm age. First quartile: 2.2-37.6; Second quartile: 37.7-49.8; Third quartile: 49.9-64.9; Fourth quartile: 65-157 Significant ones are in boldface
}

When stratified by PAM50 subtype, the overall survival was markedly worse in the patients with HER2-enriched or Basal-like breast cancer than those with Luminal A or B breast cancer $(P$ for interaction $=0.016$ ), while this phenomenon did not occur for recurrence-free survival.

\section{Discussion}

Although younger DNAm age of normal tissues was widely showed to be associated with better health outcomes in previous studies [7-17], the present study showed that younger DNAm age in the cancerous tissues of breast would predict a poorer prognosis. Since a higher DNAm age means that the individual is at an older age than chronological age, which is likely induced by harmful environmental exposures, unhealthy lifestyles, susceptible heredity, or stochastic events, it is reasonable for an accelerated DNAm age of health tissues to be connected with poorer health status. However, the situations might be different in 
Table 2 Association of overall and five-year survival with DNA methylation age

\begin{tabular}{|c|c|c|c|c|c|c|c|}
\hline \multirow[t]{2}{*}{ DNAm Age } & \multirow[t]{2}{*}{$\mathrm{N}$} & \multicolumn{3}{|l|}{ Overall survival } & \multicolumn{3}{|l|}{ Five-year survival } \\
\hline & & $\mathrm{HR}(95 \% \mathrm{Cl})^{\mathrm{a}}$ & $\mathrm{HR}(95 \% \mathrm{Cl})^{\mathrm{b}}$ & $\mathrm{HR}(95 \% \mathrm{Cl})^{\mathrm{c}}$ & $\mathrm{HR}(95 \% \mathrm{Cl})^{\text {a }}$ & $\mathrm{HR}(95 \% \mathrm{Cl})^{\mathrm{b}}$ & $\mathrm{HR}(95 \% \mathrm{Cl})^{\mathrm{c}}$ \\
\hline \multicolumn{8}{|l|}{ Continuous } \\
\hline (Per ten year) & 1076 & $1.01(0.94-1.08)$ & $0.92(0.85-1.00)$ & $0.94(0.86-1.02)$ & $0.92(0.84-1.01)$ & $0.84(0.75-0.93)$ & $0.85(0.76-0.96)$ \\
\hline \multicolumn{8}{|c|}{ Categorical (quartile) $^{d}$} \\
\hline First & 269 & 1.00 (Ref) & 1.00 (Ref) & 1.00 (Ref) & 1.00 (Ref) & 1.00 (Ref) & 1.00 (Ref) \\
\hline Second & 269 & $0.80(0.51-1.26)$ & $0.66(0.42-1.05)$ & $0.64(0.39-1.04)$ & $0.59(0.34-1.03)$ & $0.49(0.28-0.85)$ & $0.52(0.29-0.92)$ \\
\hline Third & 269 & $0.79(0.51-1.24)$ & $0.56(0.35-0.89)$ & $0.56(0.34-0.93)$ & $0.66(0.39-1.12)$ & $0.46(0.27-0.78)$ & $0.49(0.27-0.87)$ \\
\hline Fourth & 269 & $1.00(0.66-1.53)$ & $0.56(0.35-0.90)$ & $0.60(0.36-1.04)$ & $0.60(0.34-1.03)$ & $0.33(0.18-0.59)$ & $0.38(0.20-0.72)$ \\
\hline$P$ for trend & & 0.939 & 0.014 & 0.065 & 0.075 & 0.001 & 0.004 \\
\hline \multicolumn{8}{|c|}{ Categorical (First quartile and second-fourth quartile) } \\
\hline First & 269 & 1.00 (Ref) & 1.00 (Ref) & 1.00 (Ref) & 1.00 (Ref) & 1.00 (Ref) & 1.00 (Ref) \\
\hline Second-Fourth & 807 & $0.86(0.61-1.22)$ & $0.59(0.41-0.86)$ & $0.60(0.40-0.91)$ & $0.61(0.41-0.93)$ & $0.42(0.27-0.65)$ & $0.47(0.29-0.76)$ \\
\hline
\end{tabular}

cancerous tissues. As we know, carcinogenesis was an evolutionary process, driven by stepwise, somatic cell mutations with sequential, sub-clonal selection, forming the so-called cancer stem cells with potential to proliferation and propagation [22, 23]. Like DNAm age of stem cells which was low and increased with the propagation in nature, lower DNAm age of cancer cells might present more vicious tumor with a more potential to proliferate [6], which supports our present result of the association between younger DNAm age and poorer prognosis of breast cancer. In addition, this result was also consistent with the following two facts: lower DNAm age in cancer cells was associated with higher rates of genetic mutations, including P53 [6]; black breast cancer patients had a worse cancer- free interval than white patients, while the formers had a lower DNAm age than the later ones [24].

The associations between DNAm age and overall survival had ever been explored in several other tumors by Lin and Wagner and the associations were varied by the tumors derived organs [18]. The overall survival was more likely to be better in patients with esophageal carcinoma or glioblastoma multiforme if the DNAm age was older, which is in line with the result of present study, while a better prognosis with a younger DNAm age was showed in patients with thyroid carcinoma or renal clear cell carcinoma. There were no significant associations for cancers of lung, pancreas, skin, uterine, colon, bladder, et al. Based on these results, Lin and

Table 3 Association of recurrence free survivals with DNA methylation age

\begin{tabular}{|c|c|c|c|c|c|c|c|}
\hline \multirow[t]{2}{*}{ DNAm Age } & \multirow[t]{2}{*}{ N } & \multicolumn{3}{|c|}{ Overall recurrence free survival } & \multicolumn{3}{|c|}{ Five-year recurrence free survival } \\
\hline & & $\mathrm{HR}(95 \% \mathrm{Cl})^{a}$ & $\operatorname{HR}(95 \% \mathrm{Cl})^{b}$ & $\mathrm{HR}(95 \% \mathrm{Cl})^{c}$ & $\mathrm{HR}(95 \% \mathrm{Cl})^{a}$ & $\mathrm{HR}(95 \% \mathrm{Cl})^{b}$ & $\operatorname{HR}(95 \% \mathrm{Cl})^{c}$ \\
\hline \multicolumn{8}{|l|}{ Continuous } \\
\hline (Per ten year) & 889 & $0.89(0.81-0.98)$ & $0.86(0.77-0.96)$ & $0.86(0.76-0.97)$ & $0.87(0.78-0.98)$ & $0.84(0.75-0.95)$ & $0.86(0.75-0.98)$ \\
\hline \multicolumn{8}{|c|}{ Categorical (quartile) $^{d}$} \\
\hline First & 215 & 1.00 (Ref) & 1.00 (Ref) & 1.00 (Ref) & 1.00 (Ref) & 1.00 (Ref) & 1.00 (Ref) \\
\hline Second & 230 & $0.82(0.48-1.39)$ & $0.76(0.44-1.31)$ & $0.77(0.43-1.36)$ & $0.77(0.43-1.36)$ & $0.70(0.39-1.25)$ & $0.71(0.39-1.31)$ \\
\hline Third & 227 & $0.82(0.49-1.37)$ & $0.72(0.42-1.23)$ & $0.70(0.39-1.29)$ & $0.76(0.43-1.36)$ & $0.65(0.36-1.17)$ & $0.68(0.36-1.32)$ \\
\hline Fourth & 217 & $0.48(0.25-0.90)$ & $0.40(0.21-0.78)$ & $0.39(0.19-0.80)$ & $0.39(0.19-0.80)$ & $0.31(0.15-0.66)$ & $0.32(0.14-0.74)$ \\
\hline$P$ for trend & & 0.031 & 0.009 & 0.014 & 0.014 & 0.003 & 0.020 \\
\hline \multicolumn{8}{|c|}{ Categorical (First quartile and second-fourth quartile) } \\
\hline First & 215 & 1.00 (Ref) & 1.00 (Ref) & 1.00 (Ref) & 1.00 (Ref) & 1.00 (Ref) & 1.00 (Ref) \\
\hline Second-Fourth & 674 & $0.71(0.46-1.08)$ & $0.64(0.41-1.00)$ & $0.66(0.39-1.09)$ & $0.64(0.40-1.02)$ & $0.57(0.35-0.93)$ & $0.62(0.35-1.07)$ \\
\hline
\end{tabular}

${ }^{\mathrm{a}}$ No adjustment

${ }^{\mathrm{b}}$ Adjusted only for chronological age (continuous)

${ }^{c}$ Adjusted for chronological age (continuous), race, clinical stage, Menopause Status, ER status, HER2 status and PAM50 subtype

${ }^{d}$ Patients were divided into quartiles according to DNAm age. First quartile: 2.2-37.6; Second quartile: 37.7-49.8; Third quartile: 49.9-64.9; Fourth quartile: 65-157

Significant ones are in boldface 
Table 4 Associations of overall survival and recurrence free survivals with DNA methylation age stratified by menopause and clinicopathological features

\begin{tabular}{|c|c|c|c|c|c|}
\hline \multirow[t]{2}{*}{ Stratified variables } & \multirow{2}{*}{$\begin{array}{l}\text { DNAm age } \\
\text { (quartile) }^{\mathrm{a}}\end{array}$} & \multicolumn{2}{|c|}{$\underline{\text { Survival }}$} & \multicolumn{2}{|c|}{ Recurrence } \\
\hline & & $\mathrm{N}$ & $\mathrm{HR}^{\mathrm{b}}(95 \% \mathrm{Cl})$ & $\bar{N}$ & $\mathrm{HR}^{\mathrm{b}}(95 \% \mathrm{Cl})$ \\
\hline \multicolumn{6}{|l|}{ Menopause Status } \\
\hline \multirow[t]{2}{*}{ Pre } & First & 80 & 1.00 (ref) & 72 & 1.00 (ref) \\
\hline & Second-Fourth & 149 & $0.87(0.30-2.58)$ & 133 & $1.16(0.42-3.21)$ \\
\hline \multirow[t]{2}{*}{ Post } & First & 153 & 1.00 (ref) & 117 & 1.00 (ref) \\
\hline & Second-Fourth & 583 & $0.40(0.24-0.69)$ & 486 & $0.58(0.29-1.16)$ \\
\hline$P$ for interaction & & & 0.3761 & & 0.963 \\
\hline \multicolumn{6}{|l|}{ Clinical stage } \\
\hline \multirow[t]{2}{*}{ Stage $|\&| \mid$} & First & 136 & 1.00 (ref) & 103 & 1.00 (ref) \\
\hline & Second-Fourth & 432 & $1.24(0.62-2.49)$ & 341 & $0.80(0.32-1.96)$ \\
\hline \multirow[t]{2}{*}{ Stage III\&IV } & First & 56 & 1.00 (ref) & 39 & 1.00 (ref) \\
\hline & Second-Fourth & 131 & $0.39(0.17-0.91)$ & 97 & $1.07(0.39-2.92)$ \\
\hline$P$ for interaction & & & 0.159 & & 0.665 \\
\hline \multicolumn{6}{|l|}{ ER status } \\
\hline \multirow[t]{2}{*}{ negative } & First & 99 & 1.00 (ref) & 77 & 1.00 (ref) \\
\hline & Second-Fourth & 79 & $0.82(0.31-2.15)$ & 61 & $0.60(0.19-1.84)$ \\
\hline \multirow[t]{2}{*}{ positive } & First & 95 & 1.00 (ref) & 67 & 1.00 (ref) \\
\hline & Second-Fourth & 493 & $0.54(0.29-0.99)$ & 385 & $0.77(0.33-1.78)$ \\
\hline$P$ for interaction & & & 0.092 & & 0.9972 \\
\hline \multicolumn{6}{|l|}{ HER2 status } \\
\hline \multirow[t]{2}{*}{ negative } & First & 156 & 1.00 (ref) & 119 & 1.00 (ref) \\
\hline & Second-Fourth & 488 & $0.92(0.51-1.64)$ & 382 & $1.14(0.57-2.31)$ \\
\hline \multirow[t]{2}{*}{ Equivocal /positive } & First & 37 & 1.00 (ref) & 25 & 1.00 (ref) \\
\hline & Second-Fourth & 81 & $0.37(0.09-1.58)$ & 63 & $0.18(0.03-1.21)$ \\
\hline P for interaction & & & 0.217 & & 0.133 \\
\hline \multicolumn{6}{|l|}{ PAM50 } \\
\hline \multirow[t]{2}{*}{ Luminal A } & First & 25 & 1.00 (ref) & 13 & 1.00 (ref) \\
\hline & Second-Fourth & 204 & $0.72(0.17-2.97)$ & 149 & $0.59(0.11-3.24)$ \\
\hline \multirow[t]{2}{*}{ Luminal B } & First & 22 & 1.00 (ref) & 16 & 1.00 (ref) \\
\hline & Second-Fourth & 100 & $0.65(0.21-2.06)$ & 73 & $0.29(0.06-1.46)$ \\
\hline \multirow{2}{*}{$\begin{array}{l}\text { HER2- } \\
\text { enriched\&Basal- } \\
\text { like }\end{array}$} & First & 84 & 1.00 (ref) & 61 & 1.00 (ref) \\
\hline & Second-Fourth & 71 & $1.91(0.67-5.41)$ & 48 & $0.66(0.17-2.53)$ \\
\hline$P$ for interaction & & & 0.016 & & 0.966 \\
\hline
\end{tabular}

${ }^{a}$ Patients were divided into quartiles according to DNAm age. First quartile: 2.2-37.6; Second quartile: 37.7-49.8; Third quartile: 49.9-64.9; Fourth quartile: 65-157 ${ }^{\mathrm{b}}$ Adjusted for chronological age (continuous), race, clinical stage, menopause Status, ER status, HER2 status and PAM50 subtype. When one of the confounders was the variable for stratifying, it was not adjusted in the model

Significant ones are in boldface

Wagner speculated that alterations of DNAm age could resemble a double edged sword [18]: on the one hand, the alterations may provide a barrier of proliferation for aging cells and prevent cancer initiation; on the other hand, they could also favor chromosomal changes that trigger other mutations, which might be the reason why increased DNAm age in different cancers had various effects on the prognosis. In the present study, it was also found that patients with different subtypes of breast cancer, such as Luminal A or B and HER2 enriched or Basal-like, had opposite associations between the DNAm age and the prognosis. Nevertheless, the comprehensive associations of DNAm age with various cancers or subtypes and the mechanisms are remained to be explored.

We further found that the association of higher DNAm age with a better prognosis might be stronger in post-menopausal than pre-menopausal patients, which was supported to some extent by the results in a recent 
published report in which accelerated DNAm age was found to be associated with breast cancer susceptibility only in postmenopausal but not pre-menopausal women [25]. It suggests that hormones may influence the associations between DNAm age and the initiation and development of breast cancer and the DNAm age may reflect the real biological age in a less-hormone condition. This is also supported by the facts that the DNAm age of female breast tissue is higher than that of their blood cells and the difference diminishes with increasing age [26]. It may also be explained by the roles of the age-associated compromised detoxification, DNA repair mechanisms and immune surveillance [27].

In the present analysis, we adjusted various factors and applied several outcomes, and the associations between DNAm age and breast cancer prognosis were consistent and quite strong. Chronological age seemed play a negative confounding role and the association between DNAm age and breast cancer prognosis was stronger when adjusted by chronological age, which can be explained by the facts that breast cancer prognosis was getting worse with the increase of chronological age [28], while DNAm age in tumors had a positive relationship with chronological age. However, the relationship between DNAm age in tumors and chronological age was weak and the negative effect on the association between DNAm age and breast cancer prognosis was not fundamental (as shown in Tables 2 and 3). As for the clinicopathological features, although the statuses of hormone receptors (ER and PR) and PAM50 subtype were associated with DNAm age, they only had a minor effect on the associations between DNAm age and breast cancer prognosis, indicating that the effect of DNAm age on breast cancer prognosis was not likely to mediate through the clinicopathological features.

We used four types of outcomes for breast cancer prognosis: overall survival, overall recurrence free survival, five-year survival, and five-year recurrence free survival, which have different clinical meanings. Overall survival means any survived patients including those who died of breast cancer as well as other diseases; the longer the time elapsed, the more patients died of other diseases. Therefore, the (five-year) recurrence free survivals might be better outcomes to estimate the prognosis specific to breast cancer, in which there was an obvious dose-response relationship between DNAm age and the outcomes (as shown in Table 3).

\section{Conclusion}

In summary, the present study found that DNAm age of the tumor tissue, which associated with menopausal status and pathological features, was a strong independent predictor of breast cancer prognosis. These results suggested that the prognosis of breast cancer was related to intrinsic biological changes, and specific molecular targets for treatment of breast cancer may be implicit, particularly for that DNAm changes are of interest suggesting possible rejuvenation and health maintenance due to the reversibility [29]. The exact mechanisms and related genetic or environmental factors for the DNAm age remain to be explored.

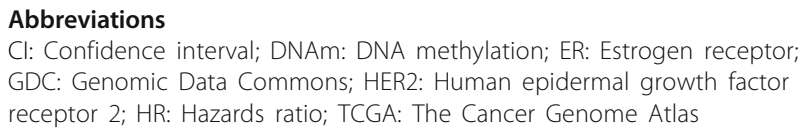

Cl: Confidence interval; DNAm: DNA methylation; ER: Estrogen receptor; GDC: Genomic Data Commons; HER2: Human epidermal growth factor receptor 2; HR: Hazards ratio; TCGA: The Cancer Genome Atlas

\section{Acknowledgements}

The results published here are in whole or part based upon data generated by The Cancer Genome Atlas (TCGA) project established by the NCl and NHGRI. Information about TCGA and the investigators and institutions which constitute the TCGA research network can be found at http://cancergenome.nih.gov.

\section{Funding}

This work was supported by the National Natural Science Foundation of China (81773515). It evoked the authors to design and perform this study.

\section{Availability of data and materials}

Information about TCGA methylation data are made publically available at http://cancergenome.nih.gov.

\section{Authors' contributions}

$J R$ and ZR conceived and designed the study. LT and MW participated in the study design. JR carried out the statistical analyses and drafted the manuscript. $J R, M W, L T$ and ZR were involved with the interpretation of the results. All authors critically revised and approved the final manuscript.

Ethics approval and consent to participate Not Applicable.

\section{Consent for publication}

Not Applicable.

\section{Competing interests}

The authors declare that they have no competing interests.

\section{Publisher's Note}

Springer Nature remains neutral with regard to jurisdictional claims in published maps and institutional affiliations.

\section{Author details}

${ }^{1}$ The School of Public Health, Sun Yat-sen University, 74 Zhongshan 2nd Road, Guangzhou 510080, People's Republic of China. 'Department of Medicine and Therapeutics, Prince of Wales Hospital, The Chinese University of Hong Kong, Shatin, Hong Kong, China. ${ }^{3}$ The Third Affiliated Hospital, Sun Yat-sen University, Guangzhou, China. ${ }^{4}$ Mailman School of Public Health, Columbia University, New York, USA

Received: 31 January 2018 Accepted: 1 October 2018

Published online: 17 October 2018

\section{References}

1. Jin K. Modern biological theories of aging. Aging Dis. 2010;1(2):72-4

2. Latorre E, Harries LW. Splicing regulatory factors, ageing and age-related disease. Ageing Res Rev. 2017;36:165-70.

3. Teschendorff AE, West J, Beck S. Age-associated epigenetic drift: implications, and a case of epigenetic thrift? Hum Mol Genet. 2013; 22(R1):R7-R15.

4. Genovese G, Kahler AK, Handsaker RE, Lindberg J, Rose SA, Bakhoum SF, Chambert K, Mick E, Neale BM, Fromer M, et al. Clonal hematopoiesis and blood-cancer risk inferred from blood DNA sequence. N Engl J Med. 2014 371(26):2477-87. 
5. Hannum G, Guinney J, Zhao L, Zhang L, Hughes G, Sadda S, Klotzle B, Bibikova M, Fan JB, Gao Y, et al. Genome-wide methylation profiles reveal quantitative views of human aging rates. Mol Cell. 2013;49(2):359-67.

6. Horvath S. DNA methylation age of human tissues and cell types. Genome Biol. 2013;14(10):R115.

7. Marioni RE, Shah S, McRae AF, Chen BH, Colicino E, Harris SE, Gibson J, Henders AK, Redmond P, Cox SR, et al. DNA methylation age of blood predicts all-cause mortality in later life. Genome Biol. 2015;16:25.

8. Zhang Y, Wilson R, Heiss J, Breitling LP, Saum KU, Schottker B, Holleczek B, Waldenberger $\mathrm{M}$, Peters $\mathrm{A}$, Brenner $\mathrm{H}$. DNA methylation signatures in peripheral blood strongly predict all-cause mortality. Nat Commun. 2017;8:14617.

9. Christiansen L, Lenart A, Tan Q, Vaupel JW, Aviv A, McGue M, Christensen K. DNA methylation age is associated with mortality in a longitudinal Danish twin study. Aging Cell. 2016;15(1):149-54.

10. Lin $\mathrm{Q}$, Weidner CI, Costa IG, Marioni RE, Ferreira MR, Deary IJ, Wagner W. DNA methylation levels at individual age-associated CpG sites can be indicative for life expectancy. Aging (Albany NY). 2016;8(2):394-401.

11. Moore AZ, Hernandez DG, Tanaka T, Pilling LC, Nalls MA, Bandinelli S, Singleton AB, Ferrucci L. Change in epigenome-wide DNA methylation over 9 years and subsequent mortality: results from the InCHIANTI study. J Gerontol A Biol Sci Med Sci. 2016;71(8):1029-35.

12. Zheng Y, Joyce BT, Colicino E, Liu L, Zhang W, Dai Q, Shrubsole MJ, Kibbe WA, Gao T, Zhang Z, et al. Blood epigenetic age may predict Cancer incidence and mortality. EBioMedicine. 2016;5:68-73.

13. Perna L, Zhang Y, Mons U, Holleczek B, Saum KU, Brenner H. Epigenetic age acceleration predicts cancer, cardiovascular, and all-cause mortality in a German case cohort. Clin Epigenetics. 2016;8:64.

14. Yang Z, Wong A, Kuh D, Paul DS, Rakyan VK, Leslie RD, Zheng SC, Widschwendter M, Beck S, Teschendorff AE. Correlation of an epigenetic mitotic clock with cancer risk. Genome Biol. 2016;17(1):205.

15. Zheng SC, Widschwendter M, Teschendorff AE. Epigenetic drift, epigenetic clocks and cancer risk. Epigenomics. 2016;8(5):705-19.

16. Durso DF, Bacalini MG, Sala C, Pirazzini C, Marasco E, Bonafe M, do Valle IF, Gentilini D, Castellani G, AMC F, et al. Acceleration of leukocytes' epigenetic age as an early tumor and sex-specific marker of breast and colorectal cancer. Oncotarget. 2017;8(14):23237-45.

17. Levine ME, Hosgood HD, Chen B, Absher D, Assimes T, Horvath S. DNA methylation age of blood predicts future onset of lung cancer in the women's health initiative. Aging (Albany NY). 2015;7(9):690-700.

18. Lin Q, Wagner W. Epigenetic aging signatures are coherently modified in Cancer. PLoS Genet. 2015;11(6):e1005334.

19. Hassan C, Afshinnekoo E, Li S, Wu S, Mason CE. Genetic and epigenetic heterogeneity and the impact on cancer relapse. Exp Hematol. 2017;54:26-30.

20. Silva TC, Colaprico A, Olsen C, D'Angelo F, Bontempi G, Ceccarelli M, Noushmehr H. TCGA workflow: analyze cancer genomics and epigenomics data using Bioconductor packages. F1000Research. 2016;5:1542.

21. Jylhava J, Pedersen NL, Hagg S. Biological age predictors. EBioMedicine. 2017;21:29-36

22. van Niekerk G, Davids LM, Hattingh SM, Engelbrecht AM. Cancer stem cells: a product of clonal evolution? Int J Cancer. 2017:140(5):993-9.

23. Chen $H$, Lin $F$, Xing $K$, He X. The reverse evolution from multicellularity to unicellularity during carcinogenesis. Nat Commun. 2015;6:6367.

24. Huo D, Hu H, Rhie SK, Gamazon ER, Cherniack AD, Liu J, Yoshimatsu TF, Pitt $\mathrm{JJ}$, Hoadley KA, Troester M, et al. Comparison of breast Cancer molecular features and survival by African and European ancestry in the Cancer genome atlas. JAMA Oncol. 2017;3:1654-62.

25. Ambatipudi S, Horvath S, Perrier F, Cuenin C, Hernandez-Vargas H, Le Calvez-Kelm F, Durand G, Byrnes G, Ferrari P, Bouaoun L, et al. DNA methylome analysis identifies accelerated epigenetic ageing associated with postmenopausal breast cancer susceptibility. Eur J Cancer. 2017;75:299-307.

26. Sehl ME, Henry JE, Storniolo AM, Ganz PA, Horvath S. DNA methylation age is elevated in breast tissue of healthy women. Breast Cancer Res Treat. 2017; 164(1):209-19.

27. Benz CC. Impact of aging on the biology of breast cancer. Crit Rev Oncol Hematol. 2008;66(1):65-74.

28. Brandt J, Garne JP, Tengrup I, Manjer J. Age at diagnosis in relation to survival following breast cancer: a cohort study. World J Surg Oncol. 2015;13:33.

29. Lopez-Otin C, Blasco MA, Partridge L, Serrano M, Kroemer G. The hallmarks of aging. Cell. 2013;153(6):1194-217.

\section{Ready to submit your research? Choose BMC and benefit from:}

- fast, convenient online submission

- thorough peer review by experienced researchers in your field

- rapid publication on acceptance

- support for research data, including large and complex data types

- gold Open Access which fosters wider collaboration and increased citations

- maximum visibility for your research: over $100 \mathrm{M}$ website views per year

At BMC, research is always in progress.

Learn more biomedcentral.com/submissions 